Article

\title{
An Exploratory Analysis of Curve Trajectories on Two-Lane Rural Highways
}

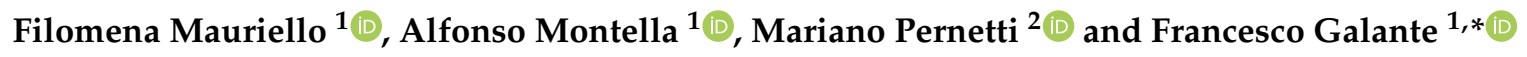 \\ 1 Department of Civil, Architectural and Environmental Engineering, University of Naples Federico II, \\ 80125 Naples, Italy; filomena.mauriello@unina.it (F.M.); alfonso.montella@unina.it (A.M.) \\ 2 Department of Engineering, University of Campania "Luigi Vanvitelli”, 81031 Aversa (Caserta), Italy; \\ mariano.pernetti@unicampania.it \\ * Correspondence: francesco.galante@unina.it; Tel.: +39-081-768-3940
}

Received: 12 October 2018; Accepted: 14 November 2018; Published: 17 November 2018

\begin{abstract}
This paper is aimed at obtaining a better understanding of driving behavior on horizontal curves of two-lane rural highways in terms of trajectories in relation to the different curve radii and directions by a driving simulator experiment. The driving simulator experiment involved 50 drivers and eight classes of curve radii, ranging from $125 \mathrm{~m}$ to $800 \mathrm{~m}$. Overall, 2000 curve trajectories were analyzed and classified. Six major classes were defined: (1) ideal behavior, (2) normal behavior, (3) driving close to the centerline, (4) driving outside in curve approach, (5) cutting, and (6) correcting. Furthermore, 21 sub-classes were introduced to consider both lane departures and location of the corrective actions. The CATANOVA tests and Bhapkar's tests showed that both the curve radius and the curve direction had a significant effect on the classification results. To get a clearer understanding of the effect of the curve radius and direction on curve negotiation, three macro-classes corresponding to safe, intermediate, and dangerous behavior were introduced. The safest behaviors significantly increased with the curve radius while the most dangerous behaviors significantly decreased with the curve radius. Furthermore, left curves showed a higher proportion of dangerous trajectories. Overall, it seems that the driving trajectories are a promising surrogate measure of safety as highlighted by the correlation between the trajectories identified as dangerous and the radii of the curves.
\end{abstract}

Keywords: driving simulator; lateral positions; curve trajectories; curve negotiation; classification

\section{Introduction}

Horizontal curves of rural two-lane highways are widely recognized as a significant safety issue. About 75 percent of all fatal crashes occur in rural areas, and more than 70 percent are on two-lane secondary highways, many of which are local roads. Although only a small portion of roadways are horizontal curve sections, nearly $25 \%$ of all fatal highway crashes occur at horizontal curve sections. The most prevalent crash types on horizontal curves are run-off-the-road and head-on crashes. In the US, these crash types account for 87 percent of the fatal crashes at horizontal curves [1] while, in Italy, for about 60 percent of the fatal crashes [2]. Accordingly, the key strategies for improving safety at horizontal curves focus on reducing the frequency and severity of these specific types of crashes. The AASHTO (American Association of State Highway and Transportation Officials) Strategic Highway Safety Plan identified as its main objective for improving safety along horizontal curves to reduce the likelihood of a vehicle leaving its lane and either crossing the roadway centerline or leaving the roadway [1].

Highway design that ensures successive elements are coordinated in such a way as to produce harmonious and homogeneous driver performance along the road is considered consistent and safe. On the other hand, an alignment which requires drivers to handle surprising events and does not meet 
drivers' expectancy is considered inconsistent and produces higher crash frequency [3-13]. Design consistency measures are generally related to the operating speed profile and the speed differential from an approach tangent to a horizontal curve. Until now, most research focused on inappropriate speed as a contributory factor of crashes on curves. However, the inability to maintain lane position is also known to contribute to driver errors on curves [14] and it is important to focus new research efforts not only on speed analyses but also on lateral positions and trajectories along horizontal curves.

Negotiating curves requires that drivers anticipate the curve by adjusting their speed and lane position to accommodate the severity of the curve. Negotiating curves thus requires more attentional resources than driving on a straight section of road [15-17]. Curve negotiation can be grouped into four distinct sections [18]: (1) approach, where drivers locate bend and make initial speed adjustments; (2) curve discovery, where drivers determine curvature, make additional speed adjustments and adjust path for curve entry; (3) entry and negotiation, where drivers adjust speed based on curvature and lateral acceleration, and maintain proper trajectory and safe lane position; and (4) exit, where drivers accelerate to appropriate speed and adjust lane position.

Charlton and de Pont [19] suggested that driver errors associated with horizontal curves are the result of three interconnected issues. First, negotiating a curve the driver's attention can more easily be diverted or the driver may fail to notice a curve ahead due to distraction, psychological fatigue, or some other factor. Sight distance through the curve (curvature) was also found to be one of the most important contributory factors associated with decreased attention. Secondly, curve approach and entry speed are often underestimated by drivers, particularly when they drive at higher speeds on the tangents before the curve [20]. Finally, poor lane positioning can lead to loss of control of the vehicle, causing run-off-the-road and head-on crashes.

Next to speed, lateral position is one of the most commonly used driving behavior metrics. Lateral position, or lane keeping, refers to the position of a vehicle on the road in relation to the center of the lane in which the vehicle is traveling. The most commonly used lateral position metrics are mean lateral position, standard deviation of lane position and the proportion of time outside of a lane [21]. Curve approaching imposes some constraints to the drivers, forcing them to change, certainly, direction and, generally, speed [22]. Drivers curve perception and their subsequent responses are highly variable and depend on the driver's personality, experience, and attitude, and on the roadway environment and vehicle characteristics [23]. This different behavior of driver on curve leads to different speed management and evolution of lateral position of vehicle. This latter represents the vehicle trajectory along the curve. The driver's path through curves often increases friction demands well beyond that anticipated by road designers by overshooting the curve and producing a vehicle path that is sharper than the actual road radius. Previous research findings revealed that steering parallel to the axis of highway is difficult. Spacek [24,25] investigated track types and classified six types: (1) ideal behavior, (2) normal behavior, (3) correcting, (4) cutting, (5) swinging, and (6) drifting. He found that most drivers followed the correcting trajectory at smaller radii curves and the cutting trajectory at larger radii. Spacek also reclassified these categories into two types: normal behavior, in which the vehicle tracks follow approximately the so-called ideal line in the center of the driving lane; and extreme behavior, in which the vehicle tracks deviate strongly from the ideal line. The extreme trajectories deviate, both consciously that unconsciously, significantly from the ideal line. The conscious extreme trajectories are generally the results of a "violation", an aberrant often speculative driving behavior inconsistent with the one suggested by road design [26]. This kind of aberrant driving behavior occurs not only inside the curve but also in curve approach and exit.

This paper is aimed at obtaining a better understanding of driving behavior on horizontal curves in terms of trajectories and classifying trajectories in relation to the different curve radii and directions. This paper is based on a driving simulator experiment that facilitates obtaining continuous lateral position profiles, thus allowing a very detailed analysis of vehicle trajectories. Driving simulators allow experiments to be conducted in controlled conditions, to collect reliable data, and to better understand interactions between drivers and roadway surroundings [27-34]. However, the use of 
driving simulators has some possible shortcomings, including: physical limitations and realism, simulator sickness, and most importantly validity $[35,36]$. The issue of validation must be addressed before the experimental results can be applied to real life situations, thus only a validated simulator can be considered as a useful research tool. Fortunately, validation of using driving simulators in highway research can be achieved.

\section{Experimental Method}

\subsection{Participants}

Fifty-four participants were involved in the study, recruited based on a preliminary questionnaire. Four subjects, 3 women and 1 man, dropped out of the experiment due to simulator sickness. Fifty participants, 33 men and 17 women with age ranging between 21 and 62 years (mean age 32.2 years, s.d. 11.4 years) completed the experiment. All the participants had a driving license with a minimum of 4 years of driving experience (mean experience 14.3 years, s.d. 10.6 years).

\subsection{Experimental Road}

The simulated road consists of a two-lane rural highway with lane width of $3.50 \mathrm{~m}$ and shoulder width of $1.25 \mathrm{~m}$. The experimental route consists of the succession of tangents with length of $800 \mathrm{~m}$ and curves radii ranging between 125 and $800 \mathrm{~m}$ with deflection angle of 45 degrees (Table 1). Long tangent sections were designed enabling drivers to reach their desired speed. The transitions between tangents and curves are carried out without spirals since most of the existing rural two-lane highways do not have spiral transitions. Cross slope is designed according to the Italian geometric design standards [37]. In the tangent, there is a crown in the middle and a $2.5 \%$ cross slope downward towards both edges. Superelevation on curves is determined based on vehicle stability with respect to skidding according to the mass-point equation $(e+f)=\frac{V^{2}}{(127 \cdot R)}$, where $\mathrm{e}=$ curve superelevation $(\mathrm{m} / \mathrm{m}), \mathrm{f}=$ side friction factor, $\mathrm{V}=$ vehicle speed $(\mathrm{km} / \mathrm{h})$, and $\mathrm{R}=$ curve radius $(\mathrm{m})$. Curve maximum superelevation is $7 \%$. Driver perception of superelevation is guaranteed by the force feedback and acceleration provided by an advanced force feedback system on the steering and a 6 degrees of freedom electric motion platform. Longitudinal grade is zero along all the route. The surrounding mimics a typical rural environment and does not present any obstacle to sight distance.

Table 1. Geometric data of the curves.

\begin{tabular}{ccccc}
\hline Type of Element & Length $(\mathbf{m})$ & Radius $(\mathbf{m})$ & Deflection Angle (Degrees) & Number of Observations \\
\hline Curve & 98.25 & 125 & 45 & 200 \\
Curve & 118.00 & 150 & 45 & 150 \\
Curve & 157.25 & 200 & 45 & 500 \\
Curve & 236.00 & 300 & 45 & 150 \\
Curve & 314.50 & 400 & 45 & 200 \\
Curve & 393.00 & 500 & 45 & 150 \\
Curve & 472.00 & 600 & 45 & 500 \\
Curve & 629.00 & 800 & 45 & 150 \\
Total & & & 2000 \\
\hline
\end{tabular}

The center line was continuous from $150 \mathrm{~m}$ before to 150 after each curve and dashed elsewhere. The edge lines were continuous for the whole experimental road. Post mounted delineators are installed on both sides of the road with a spacing of $50 \mathrm{~m}$ in the tangents and $20 \mathrm{~m}$ in the curves. The surroundings were modelled to mimic as closely as possible a real rural environment. Occasional traffic going in driver's opposite direction was simulated. A $5 \mathrm{~km}$ "warm up" section was added before the beginning of the test track. 


\subsection{Apparatus}

The experiment was conducted in the VERA (Virtual Environment for Road sAfety; Figure 1) dynamic-driving simulator, operating at the Road Safety Laboratory of University of Naples Federico II in Italy.
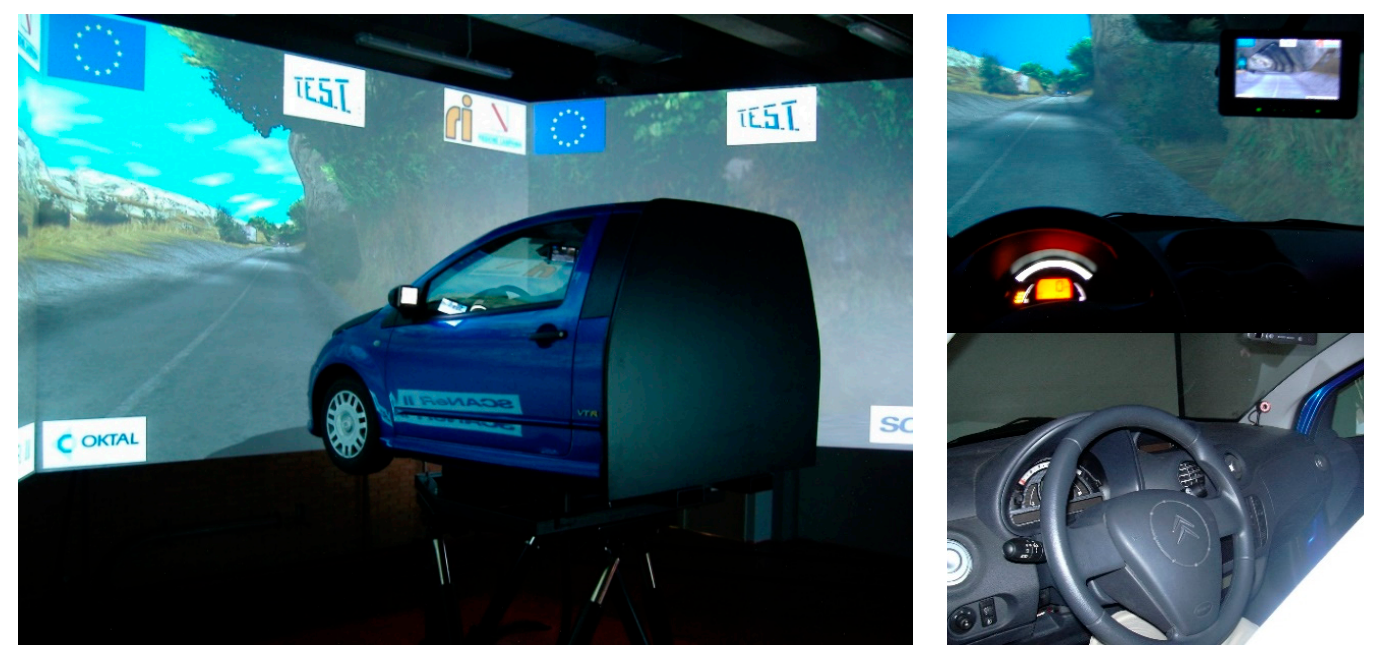

Figure 1. VERA driving simulator.

The simulator cockpit is one half of a real Citroen C2, equipped with standard driver controls and instrumentation and mounted on a motion platform. Three flat screens $(3.00 \times 4.00 \mathrm{~m})$ are located around the cockpit. The visual scene is projected to a high-resolution 3-channel $180^{\circ} \times 50^{\circ}$ forward field of view with rear and side mirror views replaced by 6,5" LCD monitors. The visual system has $1400 \times 1050$ pixels resolution for each channel and a rate of 60 frames per seconds, creating the illusion of smooth movement. Furthermore, the driving simulator is equipped with a 5.1-channel 3D sound system, which provide the driver with various sounds that can normally be heard while driving, including the rolling, engine, and exhaust noise produced by the driving vehicle as well as the surrounding sound field from other vehicles. Feedback is provided by a force feedback system (SENSO-Wheel SD-LC) on the steering and on a 6 degrees of freedom electric motion platform. The torque feedback at the steering wheel is provided via a motor fixed at the end of the steering column. Maximum torque is $16.5 \mathrm{Nm}$ with an accuracy of 0.009 degrees. The motion system consists of an hexapod with 6 electric actuators, able to reproduce most of the accelerations that real car occupants feel, in particular those arising from turning and braking maneuvers, from tire behavior in on-center handling maneuvers [38] and from dynamic interaction between the vehicle and the pavement surface unevenness [39]. The driving simulation software used in VERA is SCANeR ${ }^{\mathrm{TM}}$ studio from AV Simulation company, Billancourt, France.

To obtain relative validity, we used data from a representative sample and we accurately modelled the road scene, giving special emphasis on cross section, surroundings, road markings, and signs. To test absolute validity, comparison between real-world and driving simulator speed data was performed in a previous study [40]. The study was carried out in Italy on a two-lane rural highway and the comparison showed that there were not significant differences between the real and the simulated speed samples.

\subsection{Experimental Procedure}

Upon their arrival in the laboratory, each participant was briefed on the requirements of the experiment and all read and signed an informed consent form. Prior to the experiment, consistently with previous studies, each participant underwent a 10 min training phase. After a break, each participant drove the experimental route. The whole experimental session lasted about $45 \mathrm{~min}$. 


\section{Data}

Driving data were continuously collected with a sampling frequency of $20 \mathrm{~Hz}$ and then were interpolated every $2 \mathrm{~m}$. The following driving parameters were directly recorded: speed, lateral position, and longitudinal acceleration.

Vehicle lateral position was calculated as the distance from the vehicle's center of gravity to the lane axis (Figure 2). The lateral position is positive if the vehicle's center of gravity is to the left of the lane axis, negative if it is to the right. It means that in left curves, the lateral position is positive when the vehicle moves inside the curve (in countries with right-hand traffic), i.e., versus the center line. In right curves, the lateral position is positive when the vehicle moves outside the curve, i.e., versus the center line. Multiple consecutive vehicle lateral position observations individuate a trace of vehicle positions along a roadway segment, namely a vehicle trajectory.

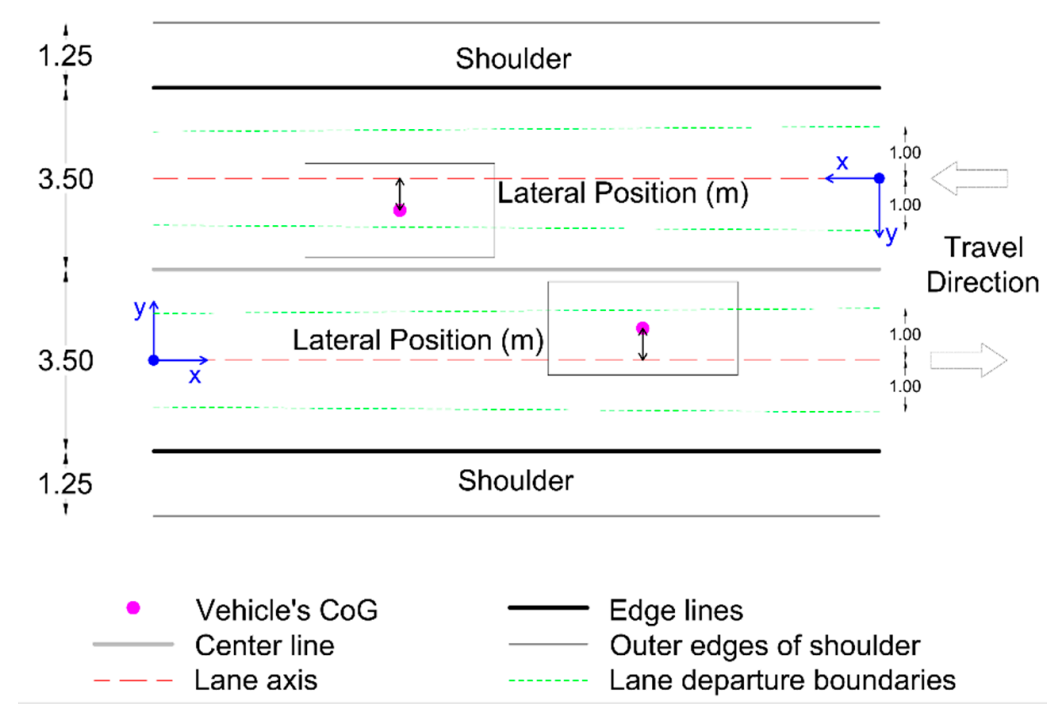

Figure 2. Lateral position definition.

The longitudinal and lateral accelerations are related to safety and comfort. Longitudinal acceleration indicates how the vehicle speed varies during the driving. The lateral acceleration $\left(a_{l}\right)$ is calculated as $a_{l}=\frac{v^{2}}{R}$, where $v$ is the vehicle speed and $R$ is the radius of the vehicle's trajectory.

Based on the previous parameters, directly recorded, we evaluated the lane departure, a common primary safety surrogate measure, that was derived in post-processing from the lane position. Since in our experiment, the lane width is $3.50 \mathrm{~m}$ and the vehicle width is $2.00 \mathrm{~m}$, a lane departure occurred when the absolute value of the lateral position was greater than $1.00 \mathrm{~m}$. Each detected lane departure was classified depending on whether the vehicle strayed from its lane in the right-side shoulder (lane departure in the shoulder, which may cause a run-off-the-road crash) or in the opposite lane (lane departure in the opposite lane, which may cause a head-on crash).

\section{Classification of Curve Trajectories}

Consistently with previous studies [18] that grouped curve negotiation in approach, discovery, entry and negotiation, and exit, curve trajectories were studied analyzing the curve itself as well as the $150 \mathrm{~m}$ preceding and following the curve. These sections were named curve approach (from $150 \mathrm{~m}$ before the curve to the point of curvature), curve (from the point of curvature to the point of tangent), and curve exit (from the point of tangent to $150 \mathrm{~m}$ after the curve).

Vehicle trajectories were classified using different combinations of the following parameters (Table 2): mean value of the lateral position $\left(\mathrm{Y}_{\text {mean }}\right)$, standard deviation of the lateral position $(\operatorname{St} . \operatorname{Dev}(\mathrm{Y}))$, maximum absolute value of the lateral position $\left(|\mathrm{Y}|_{\max }\right)$, maximum absolute value of the difference between maximum and minimum values of the lateral position $(|\Delta Y| \max )$, maximum 
and minimum values of the lateral position $\left(\mathrm{Y}_{\max }, \mathrm{Y}_{\min }\right)$, and maximum value of the lateral acceleration $\left(a_{\text {lat_max }}\right)$. Based on these parameters, six major classes were defined: (1) ideal behavior, (2) normal behavior, (3) driving close to the centerline, (4) driving outside in curve approach, (5) cutting, and (6) correcting. Furthermore, 21 sub-classes were introduced to consider both lane departures and location of the corrective actions. The class "others" was introduced to classify trajectories not falling into previous classes. It is worthwhile to observe that the classes ideal behavior, normal behavior, cutting, and correcting were already used by Spacek [24,25] but the previous studies did not use formal quantitative classification rules. The classes driving close to the centerline and driving outside in curve approach have been introduced in this study to consider specific common behaviors that cannot be classified in the previous classes. The classes swinging and drifting introduced in the previous studies were not consistent with the drivers' behavior observed in this study. One explanation of this discrepancy may be due to the difference between the spot data used in the previous studies and the continuous data used in this experiment.

Table 2. Criteria for classification of the trajectories.

\begin{tabular}{|c|c|c|c|c|}
\hline Class & Approach & Curve & Exit & Total \\
\hline 1 Ideal behavior & $\begin{array}{l}\text { St.Dev }(\mathrm{Y}) \leq 0.30 \mathrm{~m} \\
|\mathrm{Y}|_{\max } \leq 0.60 \mathrm{~m}\end{array}$ & $\begin{array}{l}\text { St.Dev }(Y) \leq 0.15 \mathrm{~m} \\
|\mathrm{Y}|_{\max } \leq 0.50 \mathrm{~m}\end{array}$ & $\begin{array}{l}\text { St.Dev }(\mathrm{Y}) \leq 0.30 \mathrm{~m} \\
|\mathrm{Y}|_{\max } \leq 0.60 \mathrm{~m}\end{array}$ & - \\
\hline 2 Normal behavior & $\begin{array}{l}\text { St.Dev }(\mathrm{Y}) \leq 0.35 \mathrm{~m} \\
|\mathrm{Y}|_{\max } \leq 0.90 \mathrm{~m} \\
|\Delta Y|_{\max } \leq 1.00 \mathrm{~m}\end{array}$ & $\begin{array}{l}\text { St.Dev }(Y) \leq 0.30 \mathrm{~m} \\
|Y|_{\max } \leq 0.80 \mathrm{~m} \\
|\Delta Y|_{\max } \leq 1.00 \mathrm{~m}\end{array}$ & $\begin{array}{l}\text { St.Dev }(\mathrm{Y}) \leq 0.35 \mathrm{~m} \\
|\mathrm{Y}|_{\max } \leq 0.90 \mathrm{~m} \\
|\Delta \mathrm{Y}|_{\max } \leq 1.00 \mathrm{~m}\end{array}$ & $\operatorname{St} \cdot \operatorname{Dev}(\mathrm{Y}) \leq 0.50 \mathrm{~m}$ \\
\hline 3 Driving close to the centerline & $\begin{array}{l}\text { St.Dev }(Y) \leq 0.35 \mathrm{~m} \\
|Y|_{\max } \leq 0.90 \mathrm{~m} \\
|\Delta Y|_{\max } \leq 1.00 \mathrm{~m}\end{array}$ & $\begin{array}{l}\text { St.Dev }(Y) \leq 0.30 \mathrm{~m} \\
\quad Y_{\text {mean }}>0.50 \mathrm{~m}\end{array}$ & $\begin{array}{l}\text { St.Dev }(Y) \leq 0.35 \mathrm{~m} \\
|Y|_{\max } \leq 0.90 \mathrm{~m} \\
|\Delta Y|_{\max } \leq 1.00 \mathrm{~m}\end{array}$ & - \\
\hline 3.1 Driving in the lane & - & $\mathrm{Y}_{\max }<0.90 \mathrm{~m}$ & - & - \\
\hline 3.2 Departure in the opposite lane & - & $\mathrm{Y}_{\max } \geq 0.90 \mathrm{~m}$ & - & - \\
\hline 4 Driving outside in curve approach & $|\mathrm{Y}|_{\max }>0.90 \mathrm{~m}$ & $\begin{array}{l}\text { St.Dev }(\mathrm{Y}) \leq 0.30 \mathrm{~m} \\
|\mathrm{Y}|_{\max } \leq 0.90 \mathrm{~m} \\
\mathrm{Y}_{\text {mean }} \leq 0.50 \mathrm{~m}\end{array}$ & $|\mathrm{Y}|_{\max } \leq 0.90 \mathrm{~m}$ & - \\
\hline 4.1 Departure in the shoulder & $\mathrm{Y}_{\min } \leq-0.90 \mathrm{~m}$ & - & - & - \\
\hline 4.2 Departure in the opposite lane & $\mathrm{Y}_{\max } \geq 0.90 \mathrm{~m}$ & - & - & - \\
\hline $\begin{array}{ll}5 \text { Cutting } & \text { right curves } \\
\text { left curves }\end{array}$ & $\begin{array}{c}Y_{\max }>0.20 \mathrm{~m} \\
Y_{\min }<-0.20 \mathrm{~m}\end{array}$ & $\begin{array}{l}\mathrm{Y}_{\min }<-0.40 \mathrm{~m} \\
\mathrm{Y}_{\max }>0.80 \mathrm{~m}\end{array}$ & $\begin{array}{l}- \\
-\end{array}$ & $|\Delta \mathrm{Y}|_{\max }>1.00 \mathrm{~m}$ \\
\hline $\begin{array}{l}\text { 5.1 Driving in the lane } \\
\text { 5.2 Departure in the shoulder } \\
\text { 5.3 Departure in the opposite lane } \\
\text { 5.4 Multiple departures }\end{array}$ & $\begin{aligned}|\mathrm{Y}|_{\max } & \leq 0.90 \mathrm{~m} \\
& - \\
- & -\end{aligned}$ & $\begin{aligned}|\mathrm{Y}|_{\max } & \leq 0.90 \mathrm{~m} \\
& - \\
- & -\end{aligned}$ & $\begin{array}{l}- \\
- \\
-\end{array}$ & $\begin{array}{c}|\mathrm{Y}|_{\max } \leq 0.90 \mathrm{~m} \\
\mathrm{Y}_{\min } \leq-0.90 \mathrm{~m} \\
\mathrm{Y}_{\max } \geq 0.90 \mathrm{~m} \\
\mid \mathrm{Y} \mathrm{I}_{\max -1,2}>0.90 \mathrm{~m}\end{array}$ \\
\hline 6 Correcting & - & - & - & $|\Delta Y|_{\max }>1.00 \mathrm{~m}$ \\
\hline 6.1 Driving in the lane & - & - & - & $|\mathrm{Y}|_{\max } \leq 0.90 \mathrm{~m}$ \\
\hline 6.1.a Correcting in the approach & $\begin{array}{l}\text { St.Dev }(Y)>0.30 \mathrm{~m} \\
\mathrm{a}_{\text {lat_max }}>4.00 \mathrm{~m} / \mathrm{s}^{2}\end{array}$ & - & - & - \\
\hline 6.1.b Correcting in the curve & - & $\begin{array}{l}\text { St.Dev }(\mathrm{Y})>0.30 \mathrm{~m} \\
\mathrm{a}_{\text {lat_max }}>4.00 \mathrm{~m} / \mathrm{s}^{2}\end{array}$ & - & - \\
\hline 6.1.c Correcting in the exit & - & - & $\begin{array}{l}\text { St.Dev }(Y)>0.30 \mathrm{~m} \\
\mathrm{a}_{\text {lat_max }}>4.00 \mathrm{~m} / \mathrm{s}^{2}\end{array}$ & - \\
\hline 6.1.d Multiple corrections & \multicolumn{4}{|c|}{ Combination of behaviors from 6.1.a to 6.1.c } \\
\hline 6.2 Departure in the shoulder & - & - & - & $\mathrm{Y}_{\min } \leq-0.90 \mathrm{~m}$ \\
\hline 6.2.a Correcting in the approach & $\begin{array}{r}\text { St.Dev }(\mathrm{Y})>0.30 \mathrm{~m} \\
\mathrm{a}_{\text {lat_max }}>4.00 \mathrm{~m} / \mathrm{s}^{2}\end{array}$ & - & - & - \\
\hline 6.2.b Correcting in the curve & - & $\begin{array}{l}\text { St.Dev }(Y)>0.30 \mathrm{~m} \\
\mathrm{a}_{\text {lat_max }}>4.00 \mathrm{~m} / \mathrm{s}^{2}\end{array}$ & - & - \\
\hline 6.2.c Correcting in the exit & - & - & $\begin{array}{l}\text { St.Dev }(Y)>0.30 \mathrm{~m} \\
\mathrm{a}_{\text {lat_max }}>4.00 \mathrm{~m} / \mathrm{s}^{2}\end{array}$ & - \\
\hline 6.2.d Multiple corrections & \multicolumn{4}{|c|}{ Combination of behaviors from 6.2.a to 6.2.c } \\
\hline 6.3 Departure in the opposite lane & - & - & - & $Y_{\max } \geq 0.90$ \\
\hline 6.3.a Correcting in the approach & $\begin{array}{l}\operatorname{St} \cdot \operatorname{Dev}(\mathrm{Y})>0.30 \mathrm{~m} \\
\mathrm{a}_{\text {lat_max }}>4.00 \mathrm{~m} / \mathrm{s}^{2}\end{array}$ & - & - & - \\
\hline 6.3.b Correcting in the curve & - & $\begin{array}{l}\operatorname{St} \cdot \operatorname{Dev}(\mathrm{Y})>0.30 \mathrm{~m} \\
\mathrm{a}_{\text {lat_max }}>4.00 \mathrm{~m} / \mathrm{s}^{2}\end{array}$ & - & - \\
\hline 6.3.c Correcting in the exit & \multirow{2}{*}{\multicolumn{4}{|c|}{$\begin{array}{l}\qquad a_{\text {lat_max }}>4.00 \mathrm{~m} / \mathrm{s}^{2} \\
\text { Combination of behaviors from 6.3.a to 6.3.c }\end{array}$}} \\
\hline 6.3.d Multiple corrections & & & & \\
\hline 6.4 Multiple departures & \multicolumn{4}{|c|}{ Combination of behaviors from 6.2 to 6.3} \\
\hline
\end{tabular}




\section{Ideal Behavior}

The ideal trajectory is almost perfectly parallel to the axis of travel lane and remains very close to it (Figure 3a). The trajectory has a very smooth progression along the curve, maximum standard deviation of lateral position of $0.15 \mathrm{~m}$ (doubling in the approach and exit sections). The distance from lane axis have not be greater than $0.5 \mathrm{~m}$ inside the curve and $0.6 \mathrm{~m}$ elsewhere.

\section{Normal Behavior}

The normal behavior is characterized by a curve negotiation without significant errors and without any lane departure (Figure 3b). This behavior is similar to the ideal but with greater values of the standard deviation and the lateral position. The normal behavior is also characterized by a maximum absolute value of the difference between maximum and minimum values of the lateral position not greater than $1.00 \mathrm{~m}$. This parameter significantly differentiates the normal behavior and the cutting.

\section{Driving Close to the Centreline}

This behavior is similar to the normal behavior but is characterized by a significant offset towards the centerline (Figure 3c). The driver uses the centerline as a reference and follows a path with the left tires close to the line. This behavior has two sub-classes: (3.1) driving in the lane and (3.2) departure in the opposite lane. The second sub-class (3.2) is associated with a greater risk of head-on crashes.

\section{Driving Outside in Curve Approach}

This behavior is similar to the normal behavior along the curve and in the curve exit. but is characterized by a significant offset towards the outside, rather than in direction of the curve, in the approach section (Figure 3d). A slight offset is common also in the normal behavior, but in this class the offset is greater than $0.90 \mathrm{~m}$ and causes a lane departure This behavior has two sub-classes: (4.1) departure in the shoulder, which occurs in the left curves, and (4.2) departure in the opposite lane, which occurs in the right curves.

\section{Cutting}

To reduce the lateral acceleration, the driver acts normally reducing the speed or increasing the radius of driven curve. This latter action is known as "cutting" the curve by tracing a trajectory with a radius greater than the geometric radius of the curve. This is a conscious driving process to balance the lateral acceleration. The cutting behavior is characterized by a maximum absolute value of the difference between maximum and minimum values of the lateral position greater than $1.00 \mathrm{~m}$. Furthermore, both maximum and minimum lateral positions must be greater or smaller than defined thresholds. This behavior has four sub-classes: (5.1) driving in the lane (Figure 3e), (5.2) departure in the shoulder, (5.3) departure in the opposite lane (Figure 3f), and (5.4) multiple departures (Figure 3g). Sub-classes 5.2, 5.3, 5.4 are associated with a greater crash risk.

\section{Correcting}

A typical, unconscious type of track behavior occurs when the driver underestimates or overestimates the curvature of the road. The driver may perceive this mistake when the vehicle is in the lane or after the vehicle leaves the lane. The mistake is usually corrected by a more or less abrupt turn of the steering wheel which causes abnormal lateral acceleration, and thus an increased demand for radial friction. If this steering correction takes place at an inappropriate speed or in presence of inadequate friction or with simultaneous braking, then the vehicle may become unstable and the crash risk significantly increases. We defined a threshold value for the lateral acceleration equal to $4 \mathrm{~m} / \mathrm{s}^{2}$. Furthermore, we also defined threshold values for the standard deviation of the lateral position, the maximum and the minimum values of the lateral position, and the maximum absolute value of the difference between maximum and minimum values of the lateral position. 


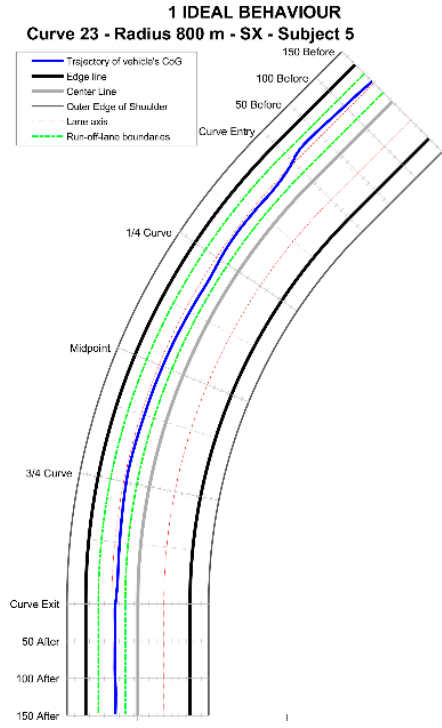

(a)

4.2 DRIVING OUTSIDE IN CURVE APPROACH Curve 28 - Radius $800 \mathrm{~m}$ - DX - Subject 18

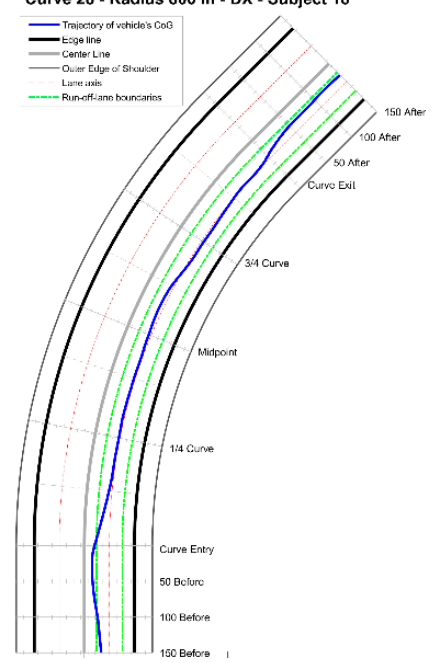

(d)

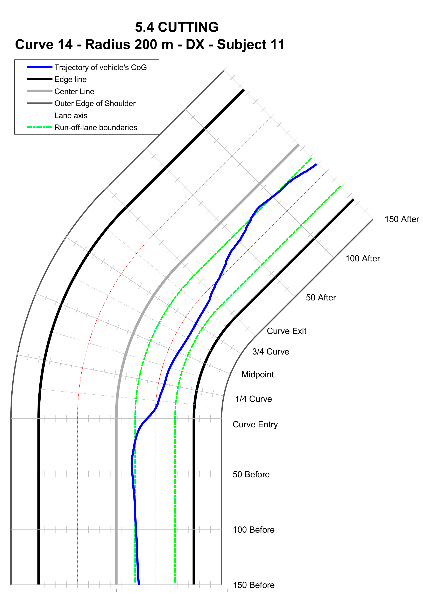

$(\mathrm{g})$

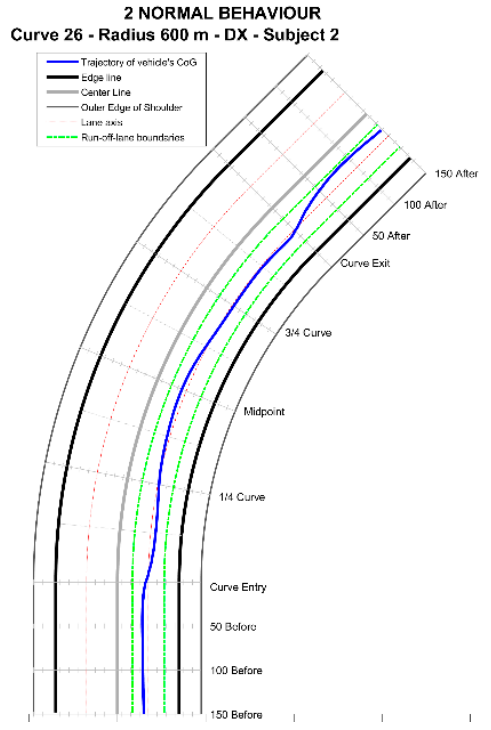

(b)

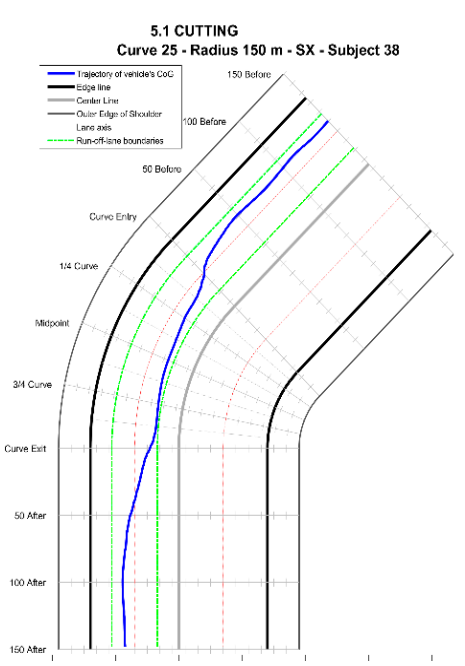

(e)

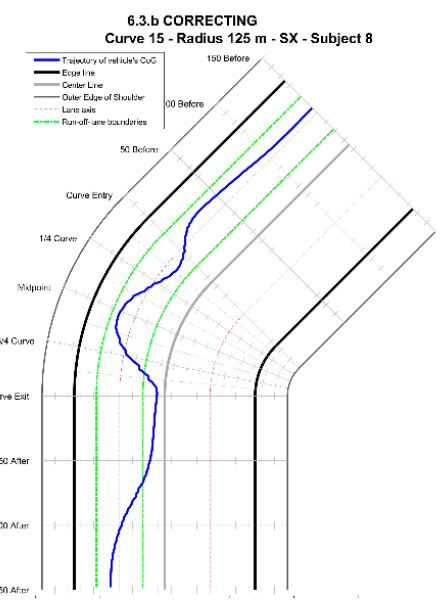

(h)

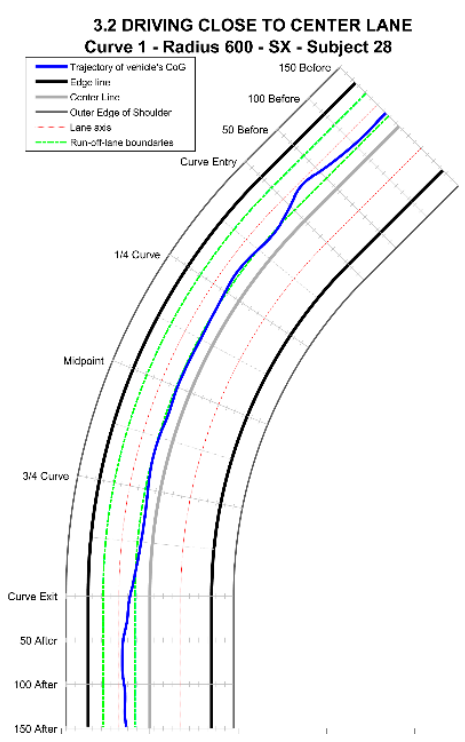

(c)

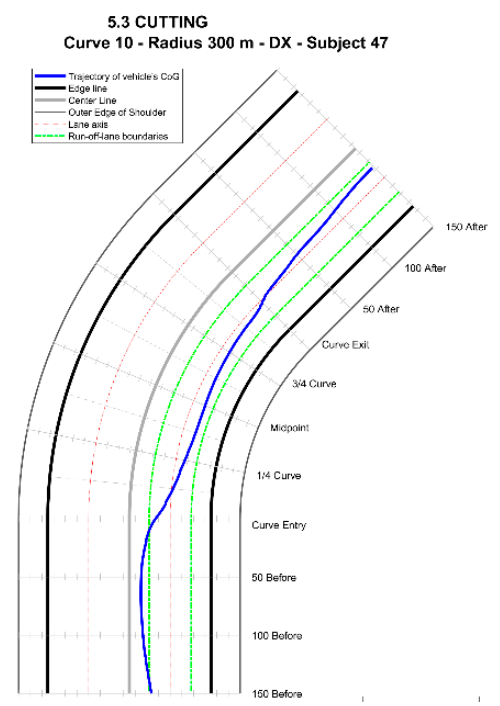

(f)

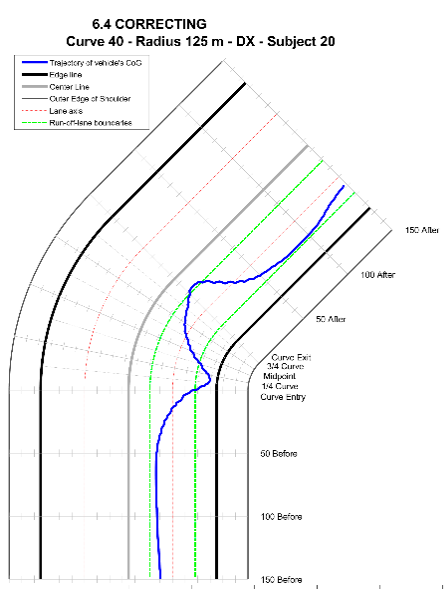

(i)

Figure 3. Sample classification of the trajectories. 
To obtain a proper classification of the correcting behavior we defined two levels of sub-classes as follows:

6.1 Driving in the lane

6.1a correcting in the curve approach

$6.1 \mathrm{~b}$ correcting in the curve

$6.1 \mathrm{c}$ correcting in the curve exit

6.1d with multiple corrections

6.2 Departure in the shoulder

6.2a correcting in the curve approach

$6.2 \mathrm{~b}$ correcting in the curve

$6.2 \mathrm{c}$ correcting in the curve exit

$6.2 \mathrm{~d}$ with multiple corrections

6.3 Departure in the opposite lane

6.3a correcting in the curve approach

$6.3 \mathrm{~b}$ correcting in the curve (Figure $3 \mathrm{~h}$ )

$6.3 \mathrm{c}$ correcting in the curve exit

$6.3 \mathrm{~d}$ with multiple corrections

6.4 Multiple departures (Figure 3i)

\section{Statistical Analysis}

We tested the statistical significance of the effect of curve radius and curve direction on the classification of the trajectories. Given the categorical data, we used the categorical analysis of variance (CATANOVA), according to the methodology developed by Light \& Margolin [41]. They introduced an analysis of variance for categorical data based on the decomposition of the heterogeneity Gini's index in the within-group and between-group sum of squares. In this analysis, the CATANOVA C-statistic is used to test the null hypothesis that the proportions of each category in all groups are equal. The approximate distribution of $C$ is chi-squared with $[($ (number of groups $)-1) \times(($ number of attributes) - 1)] degrees of freedom. Furthermore, match-pairs comparison between alternatives was performed using the non-parametric Bhapkar's test [42]. It tests marginal homogeneity for all categories simultaneously. Marginal homogeneity refers to equality (lack of significant difference) between one or more of the row marginal proportions and the corresponding column proportion(s) in a contingency table between two categorical variables.

\section{Results and Discussion}

As expected, a very small proportion of the drivers (2\%) assumed an ideal behavior (Table 3 ). The normal behavior (class 2) was quite common and was adopted by $27 \%$ of the drivers. Average values of the maximum absolute lateral position and the standard deviation of the lateral position in curve were respectively 0.61 and $0.20 \mathrm{~m}$. These values are indicative of proper driving behavior along the curve. Driving close to the centerline (class 3) was assumed by $8 \%$ of the drivers and was adopted only in left curves, indicating the tendency of drivers in left curves to drive far from the outside of the curve which is perceived as more dangerous than the inside. However, in most of these trajectories, lane departure in the opposite lane was observed (class 3.2, $7 \%$ of the total trajectories). In curve approach and exit, the driving parameters were similar to the ones of the normal behavior but, in the curve, there was a very high value of the maximum absolute lateral position, i.e., $1.12 \mathrm{~m}$. This is equivalent to an average encroachment in the opposing lane of $0.22 \mathrm{~m}$. Driving outside in curve approach (class 4) was assumed by less than $5 \%$ of the drivers, with the departure in the opposite lane (class 4.2) in 
most cases. Average encroachment in the shoulder was $0.24 \mathrm{~m}$ while average encroachment in the opposing lane was $0.22 \mathrm{~m}$. The most common behavior was the cutting (class 5), observed in $31 \%$ of the trajectories. In one third of the cutting there was not lane departure (class 5.1) while the most common sub-category was the departure in the opposite lane when cutting the apex of the curve (class 5.3). The cutting maneuvers were characterized by a large value of $|\Delta \mathrm{Y}|{ }_{\max }: 1.45 \mathrm{~m}$ for cutting vs. $0.85 \mathrm{~m}$ for normal behavior. An important result is that the correcting behavior (class 6) was observed in more than one fourth of the maneuvers. The most common correction type involved the departure in the opposite lane (class $6.3,16.2 \%$ of the trajectories). Correcting drivers who depart in the opposing lane exhibit in most case multiple corrections (class 6.3.d, $7 \%$ of the trajectories). This occurs because drivers perceive as dangerous an unintentional departure in the opposite lane and tend to overcorrect, thus requiring a second correction to adjust the effects of the first correction. The correction trajectories were characterized by the large value of $|\Delta \mathrm{Y}|_{\max }: 1.54 \mathrm{~m}$ for correction vs. $1.45 \mathrm{~m}$ for cutting.

Table 3. Classification results.

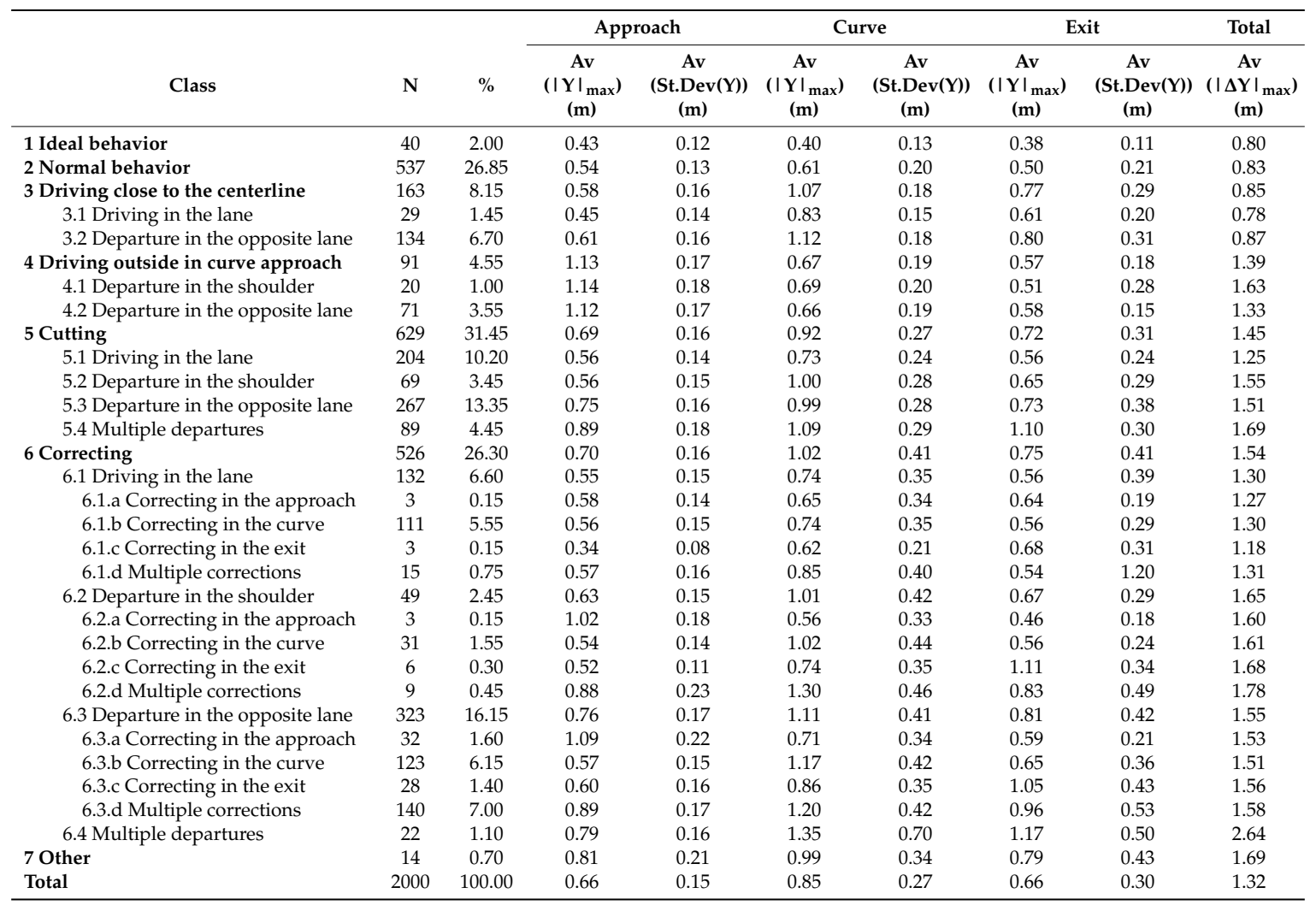

Table 4 shows the proportion of the different classes of trajectory disaggregated in relation to the curve radius and direction. Differences in the proportions are statistically significant, as highlighted by the results of the statistical tests (Table 5). The CATANOVA test shows that the curve radius had a significant effect on the classification results $(p<0.001)$. The Bhapkar's test shows a statistically significant effect between all classes of radius. The only not significant differences are $R_{300} v s . R_{200}, R_{400}$ vs. $R_{300}, R_{500}$ vs. $R_{400}$, and $R_{600}$ vs. $R_{500}$. The Bhapkar's test shows that overall effect of curve direction is statistically significant $(p<0.001)$ while the effect for the single classes of radius is significant for radii of $200 \mathrm{~m}, 400 \mathrm{~m}, 600 \mathrm{~m}$, and $800 \mathrm{~m}$ (Table 5). 
Table 4. Classification results disaggregated by curve radius and direction (\%).

\begin{tabular}{|c|c|c|c|c|c|c|c|c|c|c|c|c|c|c|c|c|c|c|}
\hline \multirow[b]{2}{*}{ Behavior } & \multicolumn{2}{|c|}{$\mathrm{R}=125 \mathrm{~m}$} & \multicolumn{2}{|c|}{$R=150 \mathrm{~m}$} & \multicolumn{2}{|c|}{$R=200 \mathrm{~m}$} & \multicolumn{2}{|c|}{$\mathrm{R}=300 \mathrm{~m}$} & \multicolumn{2}{|c|}{$\mathrm{R}=400 \mathrm{~m}$} & \multicolumn{2}{|c|}{$\mathrm{R}=500 \mathrm{~m}$} & \multicolumn{2}{|c|}{$R=600 \mathrm{~m}$} & \multicolumn{2}{|c|}{$\mathrm{R}=800 \mathrm{~m}$} & \multicolumn{2}{|c|}{ Total } \\
\hline & Left & Right & Left & Right & Left & Right & Left & Right & Left & Right & Left & Right & Left & Right & Left & Right & Left & Right \\
\hline 1 Ideal behavior & 0.0 & 2.0 & 0.0 & 4.0 & 0.0 & 1.2 & 2.0 & 0.0 & 1.0 & 2.0 & 2.0 & 4.0 & 5.2 & 2.0 & 4.0 & 2.0 & 2.0 & 2.0 \\
\hline 2 Normal behavior & 7.0 & 14.1 & 20.0 & 21.0 & 20.8 & 21.2 & 16.0 & 28.0 & 25.0 & 26.0 & 31.0 & 28.0 & 37.2 & 36.8 & 48.0 & 45.0 & 25.8 & 27.9 \\
\hline 3 Driving close to the centerline & 3.0 & 0.0 & 2.0 & 0.0 & 12.8 & 0.0 & 13.0 & 0.0 & 21.0 & 0.0 & 19.0 & 0.0 & 24.4 & 0.0 & 26.0 & 0.0 & 16.3 & 0.0 \\
\hline 3.1 Driving in the lane & 1.0 & 0.0 & 0.0 & 0.0 & 0.0 & 0.0 & 3.0 & 0.0 & 2.0 & 0.0 & 6.0 & 0.0 & 6.0 & 0.0 & 4.0 & 0.0 & 2.9 & 0.0 \\
\hline 3.2 Departure in the opposite lane & 2.0 & 0.0 & 2.0 & 0.0 & 12.8 & 0.0 & 10.0 & 0.0 & 19.0 & 0.0 & 13.0 & 0.0 & 18.4 & 0.0 & 22.0 & 0.0 & 13.4 & 0.0 \\
\hline 4 Driving outside in curve approach & 1.0 & 2.0 & 0.0 & 1.0 & 0.8 & 6.8 & 4.0 & 4.0 & 2.0 & 7.0 & 3.0 & 14.0 & 2.8 & 10.4 & 2.0 & 9.0 & 2.0 & 7.1 \\
\hline 4.1 Departure in the opposite lane & 0.0 & 2.0 & 0.0 & 1.0 & 0.0 & 6.8 & 0.0 & 4.0 & 0.0 & 7.0 & 0.0 & 14.0 & 0.0 & 10.4 & 0.0 & 9.0 & 0.0 & 7.1 \\
\hline 4.2 Departure in the shoulder & 1.0 & 0.0 & 0.0 & 0.0 & 0.8 & 0.0 & 4.0 & 0.0 & 2.0 & 0.0 & 3.0 & 0.0 & 2.8 & 0.0 & 2.0 & 0.0 & 2.0 & 0.0 \\
\hline 5 Cutting & 36.0 & 31.3 & 30.0 & 30.0 & 35.2 & 36.8 & 35.0 & 44.0 & 34.0 & 47.0 & 29.0 & 38.0 & 16.8 & 32.0 & 10.0 & 24.0 & 28.4 & 34.5 \\
\hline 5.1 Driving in the lane & 9.0 & 13.1 & 4.0 & 11.0 & 7.2 & 12.4 & 10.0 & 8.0 & 11.0 & 16.0 & 7.0 & 16.0 & 4.4 & 16.4 & 8.0 & 8.0 & 7.2 & 13.2 \\
\hline 5.2 Departure in the shoulder & 0.0 & 3.0 & 0.0 & 3.0 & 2.0 & 5.2 & 1.0 & 6.0 & 0.0 & 8.0 & 1.0 & 8.0 & 0.4 & 7.6 & 0.0 & 8.0 & 0.8 & 6.1 \\
\hline 5.3 Departure in the opposite lane & 21.0 & 9.1 & 16.0 & 11.0 & 25.6 & 12.4 & 17.0 & 22.0 & 15.0 & 18.0 & 13.0 & 10.0 & 9.6 & 5.6 & 0.0 & 6.0 & 16.2 & 10.5 \\
\hline 5.4 Multiple departures & 6.0 & 6.1 & 10.0 & 5.0 & 0.4 & 6.8 & 7.0 & 8.0 & 8.0 & 5.0 & 8.0 & 4.0 & 2.4 & 2.4 & 2.0 & 2.0 & 4.2 & 4.7 \\
\hline 6 Correcting & 52.0 & 50.5 & 48.0 & 44.0 & 29.2 & 34.0 & 30.0 & 24.0 & 17.0 & 18.0 & 15.0 & 16.0 & 13.2 & 18.8 & 6.0 & 15.0 & 24.7 & 27.9 \\
\hline 6.1 Driving in the lane & 6.0 & 18.2 & 4.0 & 12.0 & 9.6 & 8.0 & 7.0 & 10.0 & 3.0 & 5.0 & 5.0 & 4.0 & 2.8 & 5.2 & 0.0 & 3.0 & 5.4 & 7.8 \\
\hline 6.1.a Correcting in the approach & 0.0 & 0.0 & 0.0 & 0.0 & 0.0 & 0.4 & 2.0 & 0.0 & 0.0 & 0.0 & 0.0 & 0.0 & 0.0 & 0.0 & 0.0 & 0.0 & 0.2 & 0.1 \\
\hline 6.1.b Correcting in the curve & 6.0 & 18.2 & 4.0 & 12.0 & 3.6 & 7.6 & 4.0 & 10.0 & 3.0 & 4.0 & 4.0 & 4.0 & 2.8 & 5.2 & 0.0 & 3.0 & 3.5 & 7.6 \\
\hline 6.1.c Correcting in the exit & 0.0 & 0.0 & 0.0 & 0.0 & 0.0 & 0.0 & 1.0 & 0.0 & 0.0 & 1.0 & 1.0 & 0.0 & 0.0 & 0.0 & 0.0 & 0.0 & 0.2 & 0.1 \\
\hline 6.1.d Multiple corrections & 0.0 & 0.0 & 0.0 & 0.0 & 6.0 & 0.0 & 0.0 & 0.0 & 0.0 & 0.0 & 0.0 & 0.0 & 0.0 & 0.0 & 0.0 & 0.0 & 1.5 & 0.0 \\
\hline 6.2 Departure in the shoulder & 0.0 & 5.1 & 2.0 & 6.0 & 0.8 & 3.2 & 0.0 & 4.0 & 0.0 & 6.0 & 2.0 & 4.0 & 0.4 & 3.6 & 0.0 & 5.0 & 0.6 & 4.3 \\
\hline 6.2.a Correcting in the approach & 0.0 & 0.0 & 2.0 & 0.0 & 0.0 & 0.0 & 0.0 & 0.0 & 0.0 & 0.0 & 1.0 & 0.0 & 0.4 & 0.0 & 0.0 & 0.0 & 0.3 & 0.0 \\
\hline 6.2.b Correcting in the curve & 0.0 & 3.0 & 0.0 & 3.0 & 0.4 & 2.0 & 0.0 & 2.0 & 0.0 & 6.0 & 1.0 & 4.0 & 0.0 & 2.8 & 0.0 & 2.0 & 0.2 & 2.9 \\
\hline 6.2.c Correcting in the exit & 0.0 & 1.0 & 0.0 & 1.0 & 0.0 & 0.4 & 0.0 & 2.0 & 0.0 & 0.0 & 0.0 & 0.0 & 0.0 & 0.4 & 0.0 & 1.0 & 0.0 & 0.6 \\
\hline 6.2.d Multiple corrections & 0.0 & 1.0 & 0.0 & 2.0 & 0.4 & 0.8 & 0.0 & 0.0 & 0.0 & 0.0 & 0.0 & 0.0 & 0.0 & 0.4 & 0.0 & 2.0 & 0.1 & 0.8 \\
\hline 6.3 Departure in the opposite lane & 42.0 & 23.2 & 38.0 & 24.0 & 18.8 & 19.6 & 22.0 & 10.0 & 13.0 & 7.0 & 8.0 & 8.0 & 10.0 & 10.0 & 6.0 & 7.0 & 17.9 & 14.4 \\
\hline 6.3.a. Correcting in the approach & 0.0 & 7.1 & 0.0 & 6.0 & 0.0 & 5.2 & 0.0 & 2.0 & 0.0 & 1.0 & 0.0 & 2.0 & 0.0 & 1.2 & 0.0 & 0.0 & 0.0 & 3.2 \\
\hline 6.3.b Correcting in the curve & 17.0 & 4.0 & 12.0 & 6.0 & 7.2 & 5.6 & 12.0 & 2.0 & 10.0 & 1.0 & 5.0 & 4.0 & 6.0 & 3.2 & 4.0 & 2.0 & 8.5 & 3.8 \\
\hline 6.3.c Correcting in the exit & 10.0 & 2.0 & 4.0 & 5.0 & 1.2 & 1.2 & 0.0 & 0.0 & 0.0 & 0.0 & 0.0 & 0.0 & 0.0 & 0.8 & 0.0 & 1.0 & 1.5 & 1.3 \\
\hline 6.3.d Multiple corrections & 15.0 & 10.1 & 22.0 & 7.0 & 10.4 & 7.6 & 10.0 & 6.0 & 3.0 & 5.0 & 3.0 & 2.0 & 4.0 & 4.8 & 2.0 & 4.0 & 7.9 & 6.1 \\
\hline 6.4 Multiple corrections & 4.0 & 4.0 & 4.0 & 2.0 & 0.0 & 3.2 & 1.0 & 0.0 & 1.0 & 0.0 & 0.0 & 0.0 & 0.0 & 0.0 & 0.0 & 0.0 & 0.8 & 1.4 \\
\hline 7 Other & 1.0 & 0.0 & 0.0 & 0.0 & 1.2 & 0.0 & 0.0 & 0.0 & 0.0 & 0.0 & 1.0 & 0.0 & 0.4 & 0.0 & 4.0 & 5.0 & 0.8 & 0.5 \\
\hline Total & 100 & 100 & 100 & 100 & 100 & 100 & 100 & 100 & 100 & 100 & 100 & 100 & 100 & 100 & 100 & 100 & 100 & 100 \\
\hline
\end{tabular}


Table 5. CATANOVA and Bhapkar's test results.

\begin{tabular}{|c|c|c|c|c|c|c|c|c|}
\hline \multicolumn{9}{|c|}{ Classes } \\
\hline Bhapkar's test & $\mathrm{R}=125 \mathrm{~m}$ & $\mathrm{R}=150 \mathrm{~m}$ & $R=200 \mathrm{~m}$ & $\mathrm{R}=300 \mathrm{~m}$ & $\mathrm{R}=400 \mathrm{~m}$ & $\mathrm{R}=500 \mathrm{~m}$ & $R=600 \mathrm{~m}$ & $\mathrm{R}=800 \mathrm{~m}$ \\
\hline $\mathrm{R}=125 \mathrm{~m}$ & 1 & 0.052 & $<0.001$ & $<0.001$ & $<0.001$ & $<0.001$ & $<0.001$ & $<0.001$ \\
\hline $\mathrm{R}=150 \mathrm{~m}$ & & 1 & $<0.001$ & $<0.001$ & $<0.001$ & $<0.001$ & $<0.001$ & $<0.001$ \\
\hline $\mathrm{R}=200 \mathrm{~m}$ & & & 1 & 0.890 & $<0.001$ & $<0.001$ & $<0.001$ & $<0.001$ \\
\hline $\mathrm{R}=300 \mathrm{~m}$ & & & & 1 & 0.103 & $<0.001$ & $<0.001$ & $<0.001$ \\
\hline $\mathrm{R}=400 \mathrm{~m}$ & & & & & 1 & 0.280 & $<0.001$ & $<0.001$ \\
\hline $\mathrm{R}=500 \mathrm{~m}$ & & & & & & 1 & 0.130 & $<0.001$ \\
\hline $\mathrm{R}=600 \mathrm{~m}$ & & & & & & & 1 & 0.026 \\
\hline $\mathrm{R}=800 \mathrm{~m}$ & & & & & & & & 1 \\
\hline \multicolumn{2}{|c|}{ CATANOVA test } & \multicolumn{2}{|c|}{$C=502.93$} & \multicolumn{2}{|c|}{$\mathrm{df}=42$} & & \multicolumn{2}{|c|}{$p$-value $<0.001$} \\
\hline \multicolumn{9}{|c|}{ Macro-classes } \\
\hline Bhapkar's test & $\mathrm{R}=125 \mathrm{~m}$ & $\mathrm{R}=150 \mathrm{~m}$ & $\mathrm{R}=200 \mathrm{~m}$ & $\mathrm{R}=300 \mathrm{~m}$ & $\mathrm{R}=400 \mathrm{~m}$ & $\mathrm{R}=500 \mathrm{~m}$ & $\mathrm{R}=600 \mathrm{~m}$ & $\mathrm{R}=800 \mathrm{~m}$ \\
\hline $\mathrm{R}=125 \mathrm{~m}$ & 1.000 & 0.007 & $<0.001$ & 0.005 & $<0.001$ & $<0.001$ & $<0.001$ & $<0.001$ \\
\hline $\mathrm{R}=150 \mathrm{~m}$ & & 1.000 & 0.550 & 0.480 & 0.004 & $<0.001$ & $<0.001$ & $<0.001$ \\
\hline $\mathrm{R}=200 \mathrm{~m}$ & & & 1.000 & 0.964 & 0.005 & $<0.001$ & $<0.001$ & $<0.001$ \\
\hline $\mathrm{R}=300 \mathrm{~m}$ & & & & 1.000 & 0.115 & 0.001 & $<0.001$ & $<0.001$ \\
\hline $\mathrm{R}=400 \mathrm{~m}$ & & & & & 1.000 & 0.249 & $<0.001$ & $<0.001$ \\
\hline $\mathrm{R}=500 \mathrm{~m}$ & & & & & & 1.000 & 0.116 & $<0.001$ \\
\hline $\mathrm{R}=600 \mathrm{~m}$ & & & & & & & 1.000 & 0.025 \\
\hline $\mathrm{R}=800 \mathrm{~m}$ & & & & & & & & 1.000 \\
\hline CATANO & A test & $C=3$ & 1.799 & & & & $p$-valu & $<0.001$ \\
\hline \multicolumn{4}{|c|}{ Classes } & & \multicolumn{4}{|c|}{ Macro-classes } \\
\hline Left vs. Right & B & $p$-Value & $\mathrm{N}$ & & $\begin{array}{l}\text { Left vs. } \\
\text { Right }\end{array}$ & B & $p$-Value & $\mathrm{N}$ \\
\hline $\mathrm{R}=125 \mathrm{~m}$ & 2.190 & 0.534 & 200 & & $\mathrm{R}=125 \mathrm{~m}$ & 9.216 & 0.027 & 200 \\
\hline $\mathrm{R}=150 \mathrm{~m}$ & 0.571 & 0.752 & 150 & & $\mathrm{R}=150 \mathrm{~m}$ & 5.301 & $\underline{0.071}$ & 150 \\
\hline $\mathrm{R}=200 \mathrm{~m}$ & 11.862 & 0.008 & 500 & & $\mathrm{R}=200 \mathrm{~m}$ & 18.904 & $\overline{<0.001}$ & 500 \\
\hline $\mathrm{R}=300 \mathrm{~m}$ & 3.948 & 0.139 & 150 & & $\mathrm{R}=300 \mathrm{~m}$ & 1.875 & 0.392 & 150 \\
\hline $\mathrm{R}=400 \mathrm{~m}$ & 8.731 & 0.013 & 200 & & $\mathrm{R}=400 \mathrm{~m}$ & 2.789 & 0.248 & 200 \\
\hline $\mathrm{R}=500 \mathrm{~m}$ & 6.233 & 0.101 & 150 & & $\mathrm{R}=500 \mathrm{~m}$ & 4.356 & 0.225 & 150 \\
\hline $\mathrm{R}=600 \mathrm{~m}$ & 45.758 & $<0.001$ & 500 & & $\mathrm{R}=600 \mathrm{~m}$ & 16.933 & 0.001 & 500 \\
\hline $\mathrm{R}=800 \mathrm{~m}$ & 13.982 & 0.003 & 150 & & $\mathrm{R}=800 \mathrm{~m}$ & 0.558 & 0.906 & 150 \\
\hline Total & 137.561 & $<0.001$ & 2000 & & Total & 43.569 & $<0.001$ & 2000 \\
\hline
\end{tabular}

Note: boldface indicates statistically significant values with $5 \%$ level of significance, underline indicates statistically significant values with $10 \%$ level of significance.

To get a clearer understanding of the effect of the curve radius on curve negotiation, we have introduced 3 macro-classes: G1 (class 1, ideal + class 2, normal), which represents the safest curve negotiation behavior; G2 (class 3.1, driving close to the centerline-driving in the lane + class 4, driving outside in curve approach + class 5.1, cutting-driving in the lane), which represents an intermediate behavior characterized by intentional encroachments before the curve to reduce the lateral acceleration (class 4) and trajectories without lane encroachments or corrections; and G3 (class $3.2+$ class $5.2+$ class 5.3 + class $5.4+$ class 6 ), which represents the most dangerous behavior characterized by lane departures in the curve or exaggerated lateral accelerations to correct driving mistakes.

As shown in Figure 4, the safest behaviors (G1) significantly increase with the curve radius. They are only the $10 \%$ of the trajectories in the curves with radius of $125 \mathrm{~m}$ while they become more almost $50 \%$ in the curves with radius of $800 \mathrm{~m}$. The intermediate behaviors (G2) show a slight increase with the curve radius. Notably, dangerous behaviors significantly decrease with curve radius: $75 \%$ in the curves with radius of $125 \mathrm{~m}$ vs. $30 \%$ in the curves with radius of $800 \mathrm{~m}$. The CATANOVA test shows that these results are statistically significant $(p<0.001)$ and the Bhapkar's test shows statistically significant differences between most classes of radius. These results are consistent with crash statistics showing a considerably higher crash rate on small radius curves $[43,44]$. 


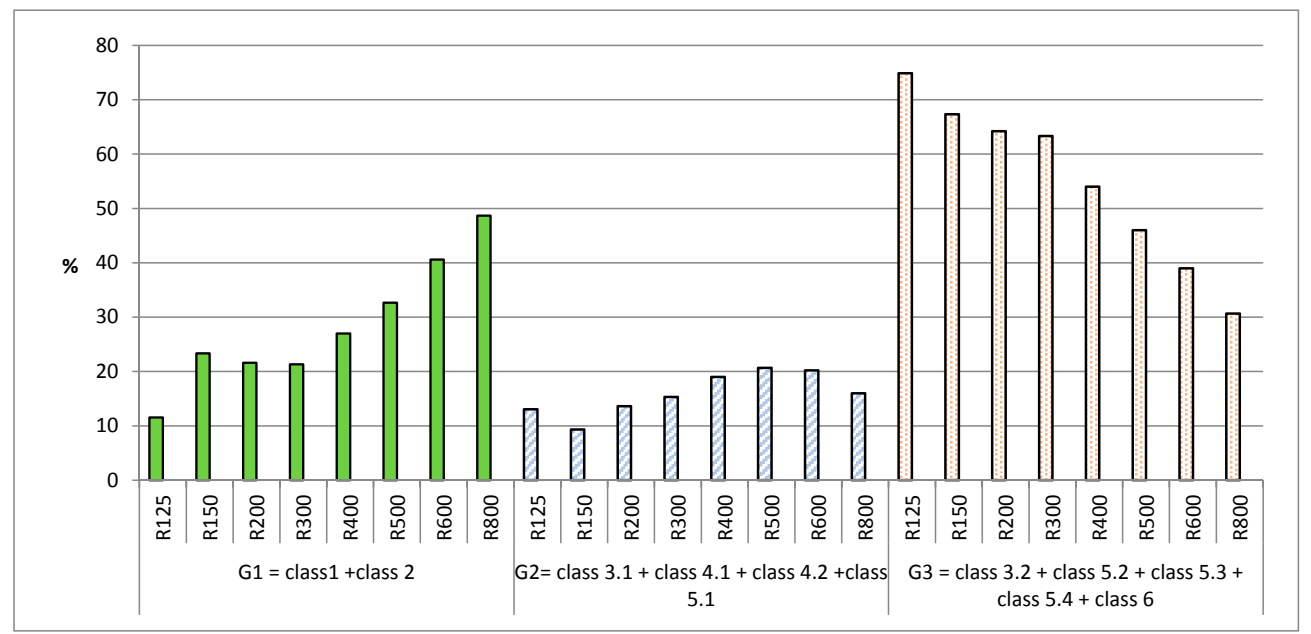

Figure 4. Macro-classification of the trajectories (G1 = class 1 + class 2; G2 = class 3.1 + class 4 + class $5.1 ; \mathrm{G} 3$ = class 3.2 + class 5.2 + class 5.3 + class $5.4+$ class 6$)$.

Furthermore, left curves show a higher proportion of dangerous trajectories, mainly because of the numerous cases of driving close to the centerline with departure in the opposite lane (class 3.2). The overall effect of curve direction is statistically significant $(p<0.001)$ while the effect for the single classes of radius is significant for radii of $125 \mathrm{~m}, 150 \mathrm{~m}, 200 \mathrm{~m}$, and $600 \mathrm{~m}$ (Table 5).

\section{Conclusions}

The driving simulator experiment performed in the study allowed analysis of drivers' behavior at horizontal curves of two-lane rural highways in terms of trajectories and to classify trajectories in relation to the different curve radii and directions.

The experiment involved 50 drivers and eight classes of curve radius, ranging from $125 \mathrm{~m}$ to $800 \mathrm{~m}$. Overall, 2000 curve trajectories were analyzed and classified. The classification was carried out according to formal and quantitative rules based on the following parameters: mean value of the lateral position, standard deviation of the lateral position, maximum absolute value of the lateral position, maximum absolute value of the difference between maximum and minimum values of the lateral position, maximum and minimum values of the lateral position, and maximum value of the lateral acceleration. Based on these parameters, six major classes were defined: (1) ideal behavior, (2) normal behavior, (3) driving close to the centerline, (4) driving outside in curve approach, (5) cutting, and (6) correcting. Furthermore, 21 sub-classes were introduced to take into account both lane departures and location of the corrective actions. The CATANOVA tests and the Bhapkar's tests showed that both the curve radius and the curve direction had a significant effect on the classification results $(p<0.001)$.

To get a clearer understanding of the effect of the curve radius and direction on curve negotiation, we have introduced 3 macro-classes: G1 which represents the safest curve negotiation behavior, G2 which represents an intermediate behavior, and G3 which represents the most dangerous behavior. The safest behaviors (G1) significantly increased with the curve radius while the most dangerous behaviors significantly decreased with the curve radius: $75 \%$ in the curves with radius of $125 \mathrm{~m}$ vs. $30 \%$ in the curves with radius of $800 \mathrm{~m}$. Overall, it seems that the driving trajectories are a promising surrogate measure of safety as highlighted by the correlation between the trajectories identified as dangerous and the radii of the curves.

Further research is needed to extend and confirm the study results. The impact on drivers' trajectories of parameters of longitudinal vehicle motion and of more geometric design features such as spiral transitions and vertical alignment shall be deeply investigated. It is noteworthy to observe that in this study the usual caveats of laboratory research must apply, in particular those relating to driver motivation and the level of perceived risk in a simulated environment. However, the drivers' behavior identified in the study was generally consistent with previous real-world and simulator studies. 
Author Contributions: All the authors confirm contribution to study conception and design, data collection, analysis and interpretation of results, and manuscript preparation. All authors reviewed the results and approved the final version of the manuscript.

Funding: This research received no external funding.

Conflicts of Interest: The authors declare no conflict of interest.

\section{References}

1. Torbic, D.J.; Harwood, D.W.; Gilmore, D.K.; Pfefer, R.; Neuman, T.R.; Slack, K.L.; Hard, K.K. NCHRP Report 500: Guidance for Implementation of the AASHTO Strategic Highway Safety Plan. Volume 7: A Guide for Reducing Collisions on Horizontal Curves; Transportation Research Board of the National Academies: Washington, DC, USA, 2004. [CrossRef]

2. Microdata. Survey on Road Accidents Resulting in Death or Injury: Public Use Micro; Italian National Institute of Statistics: Rome, Italy, 2016; Available online: https://www.istat.it/en/archivio/87804 (accessed on 16 November 2018).

3. Anderson, I.B.; Bauer, K.M.; Harwood, D.W.; Fritzpatrick, L. Relationship to safety of geometric design consistency measures for rural two-lane highways. Transp. Res. Rec. 1999, 1658, 43-51. [CrossRef]

4. Cafiso, S.; La Cava, G.; Montella, A. Safety inspections as supporting tool for safety management of low-volume roads. Transp. Res. Rec. 2011, 2203, 116-125. [CrossRef]

5. Camacho-Torregrosa, F.J.; Pérez-Zuriaga, A.M.; Campoy-Ungría, J.M.; García, A. New geometric design consistency model based on operating speed profiles for road safety evaluation. Accid. Anal. Prev. 2013, 61, 33-42. [CrossRef] [PubMed]

6. Lamm, R.; Psarianos, B.; Mailaender, T.; Choueiri, E.M.; Heger, R.; Steyer, R. Highway Design and Traffic Safety Engineering Handbook, 1st ed.; McGraw-Hill: New York, NY, USA, 1999; ISBN 0070382956.

7. Montella, A. Safety reviews of existing roads: Quantitative safety assessment methodology. Transp. Res. Rec. 2005, 1922, 62-72. [CrossRef]

8. Montella, A. Safety evaluation of curve delineation improvements: Empirical bayes observational before and after study. Transp. Res. Rec. 2009, 2103, 69-79. [CrossRef]

9. Montella, A. A comparative analysis of hotspot identification methods. Accid. Anal. Prev. 2010, 42, 571-581. [CrossRef] [PubMed]

10. Montella, A.; Colantuoni, L.; Lamberti, R. Crash prediction models for rural motorways. Transp. Res. Rec. 2008, 2083, 180-189. [CrossRef]

11. Montella, A.; Persaud, B.; D'Apuzzo, M.; Imbriani, L.L. Safety evaluation of an automated section speed enforcement system. Transp. Res. Rec. 2012, 2281, 16-25. [CrossRef]

12. Montella, A.; Imbriani, L.L. Safety performance functions incorporating design consistency variables. Accid. Anal. Prev. 2015, 74, 133-144. [CrossRef] [PubMed]

13. Montella, A.; Imbriani, L.L.; Marzano, V.; Mauriello, F. Effects on speed and safety of point-to-point speed enforcement systems: Evaluation on the urban motorway A56 Tangenziale di Napoli. Accid. Anal. Prev. 2015, 75, 164-178. [CrossRef] [PubMed]

14. Hallmark, S.L.; Hawkins, N.; Smadi, O. Relationship between Speed and Lateral Position on Curves. In Proceedings of the 16th Road Safety on Four Continents Conference, Beijing, China, 15-17 May 2013.

15. Cafiso, S.; D'Agostino, C. Reliability-based assessment of Benefits in roadway safety management. Transp. Res. Rec. 2015, 2513, 1-10. [CrossRef]

16. Cafiso, S.; D'Agostino, C. Assessing the stochastic variability of the Benefit-Cost ratio in roadway safety management. Accid. Anal. Prev. 2016, 93, 189-197. [CrossRef] [PubMed]

17. Charlton, S.G. The role of attention in horizontal curves: A comparison of advance warning, delineation, and road marking treatments. Accid. Anal. Prev. 2007, 39, 873-885. [CrossRef] [PubMed]

18. Campbell, J.L.; Lichty, M.G.; Brown, J.L.; Richard, C.M.; Graving, J.S.; Graham, J.; O’Laughlin, M.; Torbic, D.; Harwood, D. NCHRP Report 600: Human Factors Guidelines for Road Systems, 2nd ed.; Transportation Research Board of the National Academies: Washington, DC, USA, 2012; ISBN 978-0-309-25816-6. Available online: http:/ / onlinepubs.trb.org/onlinepubs/nchrp/nchrp_rpt_600second.pdf (accessed on 16 November 2018). 
19. Charlton, S.G.; De Pont, J.J. Curve Speed Management; Land Transport New Zealand Research Report 323; Land Transport New Zealand: Wellington, New Zealand, 2007; ISBN 0-478-28735-6. Available online: https:/ / www.nzta.govt.nz/assets/resources/research/reports/323/docs/323.pdf (accessed on 16 November 2018).

20. Cafiso, S.; D'Agostino, C.; Persaud, B. Investigating the influence on safety of retrofitting Italian motorways with barriers meeting a new EU standard. Traffic Inj. Prev. 2017, 18, 324-329. [CrossRef] [PubMed]

21. Fisher, D.L.; Rizzo, M.; Caird, J.; Lee, J.D. Handbook of Driving Simulation for Engineering, Medicine, and Psychology, 1st ed.; CRC Press (Taylor \& Francis Group): Boca Raton, FL, USA, 2011; ISBN 9781138074583.

22. Montella, A.; Pariota, L.; Galante, F.; Imbriani, L.L.; Mauriello, F. Prediction of drivers' speed behavior on rural motorways based on an instrumented vehicle study. Transp. Res. Rec. 2014, 2434, 52-62. [CrossRef]

23. Shinar, D. Traffic Safety and Human Behavior, 2nd ed.; Emerald Group Publishing Limited: Bingley, West Yorkshire, UK, 2017; ISBN 9781786352224.

24. Spacek, P. Track behaviour and accident occurrence in curves on two-lane highway in rural areas. In Proceedings of the 2nd International Symposium on Highway Geometric Design, Transportation Research Board, Mainz, Germany, 14-17 June 2000; pp. 288-298.

25. Spacek, P. Track behaviour in curve areas: An attempt at typology. J. Transp. Eng. 2005, 131, 669-676. [CrossRef]

26. Reason, J.; Manstead, A.; Stradling, S.; Baxter, J.; Campbell, K. Errors and violations on the roads: A real distinction? Ergonomics 1990, 33, 1315-1332. [CrossRef] [PubMed]

27. Montella, A.; Galante, F.; Imbriani, L.L.; Mauriello, F.; Pernetti, M. Simulator evaluation of drivers' behaviour on horizontal curves of two-lane rural highways. Adv. Transp. Stud. Int. J. 2014, 34, 91-104.

28. Montella, A.; Aria, M.; D’Ambrosio, A.; Galante, F.; Mauriello, F.; Pernetti, M. Perceptual measures to influence operating speeds and reduce crashes at rural intersections: Driving simulator experiment. Transp. Res. Rec. 2010, 2149, 11-20. [CrossRef]

29. Montella, A.; Aria, M.; D'Ambrosio, A.; Galante, F.; Mauriello, F.; Pernetti, M. Simulator evaluation of drivers' speed, deceleration and lateral position at rural intersections in relation to different perceptual cues. Accid. Anal. Prev. 2011, 43, 2072-2084. [CrossRef] [PubMed]

30. Montella, A.; Galante, F.; Mauriello, F.; Pariota, L. Low-cost measures for reducing speeds at curves of two-lane rural highways. Transp. Res. Rec. 2015, 2472, 142-154. [CrossRef]

31. Montella, A.; Galante, F.; Mauriello, F.; Aria, M. Continuous speed profiles to investigate drivers' behavior on two-lane rural highways. Transp. Res. Rec. 2015, 2521, 3-11. [CrossRef]

32. Montella, A.; Galante, F.; Mauriello, F.; Pariota, L. Effects of traffic control devices on rural curve driving behaviour. Transp. Res. Rec. 2015, 2492, 10-22. [CrossRef]

33. Yan, X.; Abdel-Aty, M.; Radwan, E.; Wang, X.; Chilakapati, P. Validating a driving simulator using surrogate safety measures. Accid. Anal. Prev. 2008, 40, 274-288. [CrossRef] [PubMed]

34. Tarko, A.; Boyle, L.; Montella, A. Emerging research methods and their application to road safety. Accid. Anal. Prev. 2013, 61, 1-2. [CrossRef] [PubMed]

35. Godley, S.T.; Triggs, T.J.; Fildes, B.N. Driving simulator validation for speed research. Accid. Anal. Prev. 2002, 34, 589-600. [CrossRef]

36. Galante, F.; Bracco, F.; Chiorri, C.; Pariota, L.; Biggiero, L.; Bifulco, G.N. Validity of mental workload measures in a driving simulation environment. J. Adv. Transp. 2018, 2018, 5679151. [CrossRef]

37. Guidelines for the Design of Road Infrastructures; D.M. n. 6792; Italian Ministry of Infrastructures and Transports: Rome, Italy, 5 November 2001. Available online: http://www.mit.gov.it/mit/mop_all.php?p_id=06126 (accessed on 16 November 2018). (In Italian)

38. Baldoni, F.; Galante, F.; Pernetti, M.; Russo, M.; Terzo, M.; Toscano, M. Tuning and objective performance evaluation of a driving simulator to investigate tyre behaviour in on-center handling manoeuvres. Vehicle Syst. Dyn. 2011, 49, 1423-1440. [CrossRef]

39. Pernetti, M.; D'Apuzzo, M.; Galante, F. A new approach to assess the influence of road roughness on driver speed behavior based on driving simulator tests. Balt. J. Road Bridge E. 2016, XI, 144-152. [CrossRef]

40. Galante, F.; Mauriello, F.; Montella, A.; Pernetti, M.; Aria, M.; D'Ambrosio, M. Traffic calming along rural highways crossing small urban communities: Driving simulator experiment. Accid. Anal. Prev. 2011, 42, 1585-1594. [CrossRef] [PubMed]

41. Light, R.J.; Margolin, B.H. An analysis of variance for categorical data. J. Am. Stat. Assoc. 1971, 66, 534-544. [CrossRef] 
42. Bhapkar, V.P. A note on the equivalence of two test criteria for hypotheses in categorical data. J. Am. Stat. Assoc. 1966, 61, 228-235. [CrossRef]

43. Van Petegem, J.W.H.; Wegman, F. Analyzing road design risk factors for run-off-road crashes in the Netherlands with crash prediction models. J. Saf. Res. 2014, 49, 121-127. [CrossRef] [PubMed]

44. Wu, Q.; Zhang, G.; Zhu, X.; Liu, X.C.; Tarefder, R. Analysis of driver injury severity in single-vehicle crashes on rural and urban roadways. Accid. Anal. Prev. 2016, 94, 35-45. [CrossRef] [PubMed] 